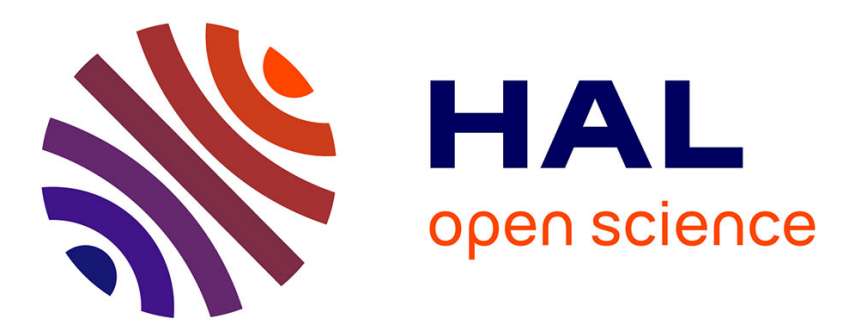

\title{
Dynamic correlation length in polymer solutions at the theta temperature
}

P. Vidakovic, C. Allain, F. Rondelez

\section{To cite this version:}

P. Vidakovic, C. Allain, F. Rondelez. Dynamic correlation length in polymer solutions at the theta temperature. Journal de Physique Lettres, 1981, 42 (13), pp.323-326. 10.1051/jphyslet:019810042013032300 . jpa-00231937

\section{HAL Id: jpa-00231937 https://hal.science/jpa-00231937}

Submitted on 1 Jan 1981

HAL is a multi-disciplinary open access archive for the deposit and dissemination of scientific research documents, whether they are published or not. The documents may come from teaching and research institutions in France or abroad, or from public or private research centers.
L'archive ouverte pluridisciplinaire HAL, est destinée au dépôt et à la diffusion de documents scientifiques de niveau recherche, publiés ou non, émanant des établissements d'enseignement et de recherche français ou étrangers, des laboratoires publics ou privés. 


\title{
Dynamic correlation length in polymer solutions at the theta temperature
}

\author{
P. Vidakovic $\left({ }^{*}\right)$, C. Allain $\left({ }^{* *}\right)$ and F. Rondelez $\left({ }^{* * *}\right)$ \\ Physique de la Matière Condensée, Collège de France, 11, place M.-Berthelot, 75231 Paris Cedex 05, France
}

(Reçu le 3 mars 1981, révisé le 14 mai, accepté le 15 mai 1981)

\begin{abstract}
Résumé. - Des mesures de sédimentation ont été effectuées dans une large gamme de concentration et de poids moléculaire sur des solutions de polystyrène-cyclohexane à $35,4^{\circ} \mathrm{C}$. L'utilisation d'une fraction de très haut poids moléculaire 20,6 $\times 10^{6}$ nous a permis de dilater le régime semi-dilué vers les faibles concentrations. On en déduit que la longueur de corrélation dynamique $\xi_{\mathrm{H}}$ suit une loi d'échelle en concentration $\xi_{\mathrm{H}} \propto c^{-0,96 \pm 0,04}$, en accord avec les prédictions théoriques.
\end{abstract}

Abstract. - Sedimentation velocity measurements have been performed in polystyrene-cyclohexane solutions at $35.4^{\circ} \mathrm{C}$. The use of extremely high molecular weight fractions, up to $20.6 \times 10^{6}$, has enabled us to study the concentration dependence of the dynamic correlation length in the semi-dilute regime. $\xi_{H}$ scales as $c^{-0.96 \pm 0.04}$ in agreement with theoretical predictions.

Coming after the mean-field description of Flory and Huggins [1], the scaling theory introduced by de Gennes [2] and des Cloizeaux [3] has permitted to describe the static and dynamic properties of flexible polymer solutions, especially in the semi-dilute regime where the chains overlap.

However this approach has been plagued by the experimental evidence in good solvents of slight differences between the static and dynamic scaling exponents of the same physical observable $[4,5]$. Recently, Weill and des Cloizeaux have suggested [6] that this discrepancy should not be attribued to a fundamental flaw in the theory but rather to the gradual change of statistics from gaussian to excludedvolume for polymer coils dissolved in good solvents [7]. On the contrary, such complications are non-existent in theta solvents where the chain statistics is gaussian at all scales (neglecting local chain rigidity and small logarithmic corrections which are negligible for all practical purposes [2]). This simplification has given us a strong incentive to start careful dynamic studies of the coil radius of gyration and of the correlation

(*) On leave of absence from Prirodno-matematicki fakultet Odsek za fizicke i meteoroloske nauke, Studentski trg 16, P.B. 550, Belgrade, Yugoslavia.

$\left({ }^{* *}\right)$ Permanent address : Laboratoire de Spectroscopie Hertzienne, Ecole Normale Supérieure, rue Lhomond, 75005 Paris, France.

(***) Author to whom requests for reprints should be addressed. length over a wide range of concentration and/or molecular weight in theta polymer solutions.

In this letter, we report on sedimentation velocity measurements performed with an analytical ultracentrifuge. In the dilute regime, our data are in good agreement with the numerous earlier determinations of the molecular weight dependence of the hydrodynamic radius of gyration. In the semi-dilute regime, our data allow to measure of the concentration dependence of the dynamic correlation length. The cross-over between these two regimes is also clearly observed.

Polystyrene-cyclohexane solutions at $35.4^{\circ} \mathrm{C}$ were selected since they represent the most widely studied case of polymer-theta solvent systems. Monodisperse fractions $\left(4.22 \times 10^{5}, 1.26 \times 10^{6}, 3.84 \times 10^{6}\right.$, $8.42 \times 10^{6}, 20.6 \times 10^{6}$ ) were obtained from the Toyo Soda Manufacturing Co. Ltd., Japan. Typical $M_{\mathrm{w}} / M_{\mathrm{n}}$ are 1.05-1.1 except for the highest molecular mass. The chains were first lyophilized from the dilute solutions in a good solvent (benzene,

$$
\left.c<10^{-4} \mathrm{~g} . \mathrm{cm}^{-3}\right) \text {, }
$$

then dispersed in hot cyclohexane and finally slowly brought to their theta point. The sedimentation runs were performed with a Spinco model $E$ analytical ultracentrifuge equipped with a schlieren optical system. The sedimentation velocity $V$ of the chains was measured by the moving boundary peak 
method [8] and converted to the sedimentation coefficient $S=V / \omega^{2} r(\omega=$ rotor angular velocity, $r=$ distance of the sample cell to the rotation axis).

In dilute solutions where the chains act as individual units, $S$ is related to the molecular mass $M$ and to the hydrodynamic size $R_{\mathrm{H}}$

$$
S \sim M / \eta R_{\mathrm{H}}
$$

where $\eta$ is the solvent viscosity.

In semi-dilute solutions where the chains overlap, Brochard and de Gennes [9] have shown that a similar equation still holds, replacing $R_{\mathrm{H}}$ by the dynamic density-density correlation length $\xi_{\mathrm{H}}$ and the total chain mass by smaller subunits, the blobs, each containing $g$ monomers. This apparently simple picture was actually obtained from a Kubo formula involving the static correlation function for the fluctuations of the monomer concentrations [2]. For gaussian chains, $g \sim c \xi_{\mathrm{s}}^{3} \sim\left(\xi_{\mathrm{s}} / a\right)^{2}$ where $\xi_{\mathrm{s}}$ is the static correlation length and $a$ the statistical length. The concentration dependence of $\xi_{\mathrm{s}}$ has been calculated by Daoud and Jannink [10] to be $\xi_{\mathrm{s}} \sim\left(c a^{2}\right)^{-1}$. This implies $g \sim\left(c a^{3}\right)^{-2}$. Assuming that the static and dynamic scaling exponents are identical in theta solvents, we obtain $\xi_{\mathrm{s}} \sim \xi_{\mathrm{H}} \sim c^{-1}$ and

$$
R_{\mathrm{H}} \sim R_{\mathrm{G}} \sim M^{1 / 2} \text {. }
$$

The sedimentation coefficient in the semi-dilute regime is therefore written very simply as

$$
S \sim c^{-1}
$$

$S$ is inversely proportional to the concentration and does not depend on molecular weight. On the other hand, the cross-over concentration $c^{*}$ between the dilute and semi-dilute regimes is reached when the monomer density within a single chain is of the order of the macroscopic monomer density. Therefore $c^{*} \sim \frac{M}{\left[R_{\mathrm{G}}\right]^{3}} \sim M^{-1 / 2}$.

The results as a function of concentration are shown on logarithmic scales in figure 1. We have used the notation $S_{\mathrm{q}}$ for the experimental values of the sedimentation coefficient $S$ to indicate that the schlieren pictures have been analysed using a quadratic fit for the position of the boundary peak versus elapsed centrifugation time. A linear fit, which neglects hydrostatic pressure and dilution effects within the sample cell, would give slightly different values, $\simeq 10 \%[11]$.

At low concentrations, the $S$ data vary by a factor of 7 over the range of chain molecular weights investigated but are only little dependent on concentration. It is customary to write $S$ in the dilute regime as $S=S_{0}\left(1+k_{\mathrm{s}} c\right)^{-1}$ where $k_{\mathrm{s}}$ is a coefficient which describes the hydrodynamic interaction between sedimenting polymer coils [12]. We observe that

$$
k_{\mathrm{s}}=(0.052 \pm 0.010) M^{1 / 2} \mathrm{~cm}^{3} \cdot \mathrm{g}^{-1} \text {, }
$$

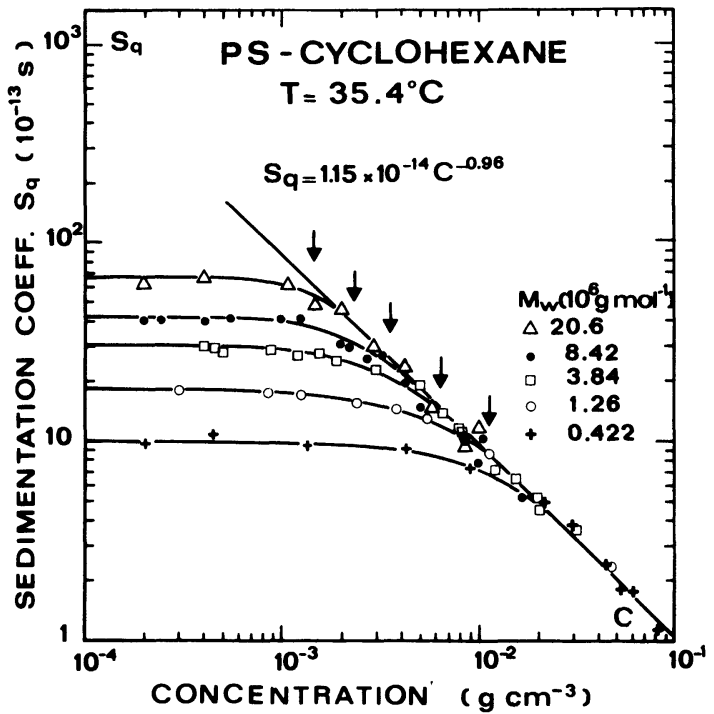

Fig. 1. - Sedimentation coefficient of different polystyrene chains $S_{\mathrm{q}}$ versus polymer concentration $c$. The typical error bar on all points is $\pm 2 \%$. The continuous lines correspond to $S_{\mathrm{q}}=S_{0}\left(1+k_{\mathrm{s}} c\right)^{-1}$ at low concentrations (see text) and to $S_{\mathrm{q}}=1.15 \times 10^{-14} c^{-0.96}$ at high concentrations but they have no precise meaning in the crossover region between these two extremes. The arrows indicate the estimated position of the cross-over concentration $c^{*}$ for each molecular weight.

close to a recent result by Mulderije [13]. In figure 2, it is shown that $S_{0}$, the extrapolated value to infinite dilution, varies with molecular weight as

$$
S_{0}=1.50 \times 10^{-15} M^{0.50},
$$

in excellent agreement with many earlier determinations [13, 14]. All these results in dilute solutions are very classical and we will not elaborate on them.

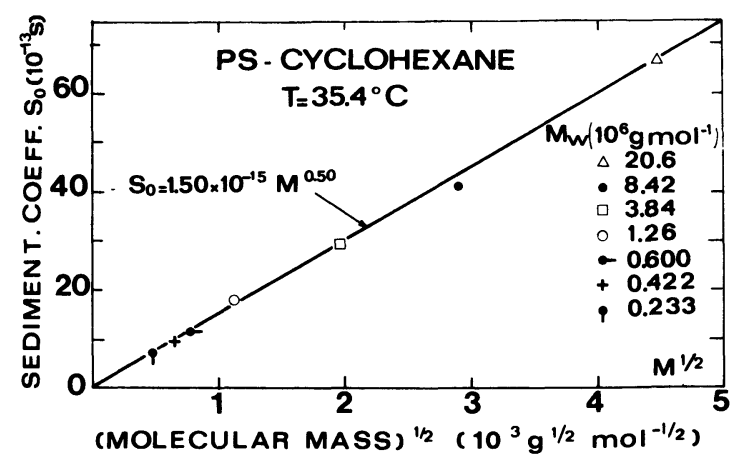

Fig. 2. - Sedimentation coefficient extrapoled at infinite dilution $S_{0}$ versus square root of molecular mass, $M^{1 / 2}$.

At high concentrations on the contrary, $S$ becomes molecular weight independent but strongly concentration dependent. Typically $S$ decreases by a factor of 50 between $2 \times 10^{-3}$ and $8 \times 10^{-2} \mathrm{~g} . \mathrm{cm}^{-3}$ when all the data points for the different molecular weights are combined. A best fit yields $S \sim c^{-\alpha}$ with

$$
\alpha=0.96 \pm 0.04 \text {. }
$$

The cross-over concentration $c^{*}$ which separates these two different concentration regimes can be 
estimated for each polymer fraction from the intersection of the straight lines passing through the lowest concentration data points for each molecular weight with the master curve at high concentrations (drawn as a solid straight line on figure 1). As shown in figure $3, c^{*}$ varies inversely proportional to the square root of the molecular mass $c^{*}=6.75 M^{-0.50}$. This value is in good agreement with the intrinsic viscosity data of Einaga et al. [15]

$$
[\eta]=8.8 \times 10^{-2} M^{0.50} \mathrm{~g}^{-1} \cdot \mathrm{cm}^{3} .
$$

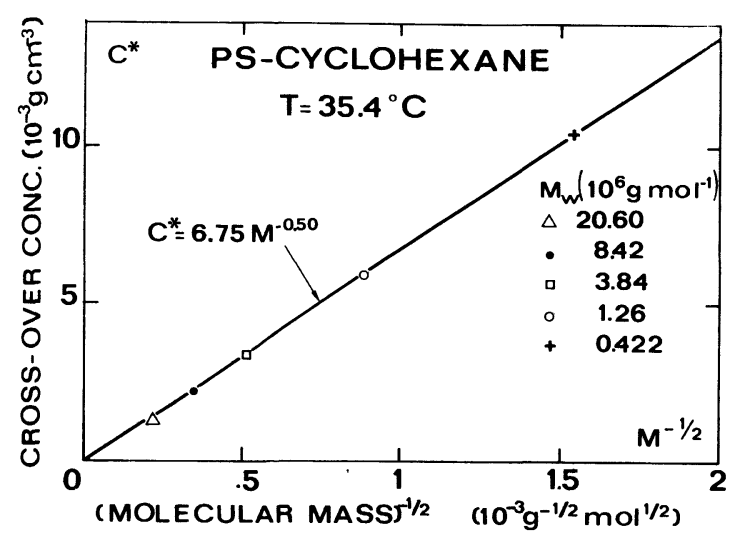

Fig. 3. - Cross-over concentration $c^{*}$ between the dilute and semi-dilute regimes, deduced from figure 1 , versus inverse root square of molecular mass, $M^{-1 / 2}$.

Indeed it is generally admitted that the product $[\eta] c^{*}$ should be a constant. Values between 0.6 and 3 have been derived from viscosity measurements by various authors $[16,17]$. Here we find that $[\eta] c^{*}=0.59 \pm 0.02$.

Sedimentation measurements in the semi-dilute regime of theta polymer solutions have already been reported, mainly by the swedish group [18] and also in the pioneering work of Mijnlieff and Jaspers [19]. However, they have been performed on relatively low molecular weight chains $\left(M \lesssim 10^{6}\right)$. In the present experiments, much higher molecular weight samples have been used. The exponent value

$$
\alpha=0.96 \pm 0.04
$$

of the dynamic screening length $\xi_{H}$ is measured with unprecedented accuracy. Roots and Nyström have also obtained independently, in a higher concentration range, a similar value of $0.95 \pm 0.06$ for $\xi_{\mathrm{H}}$ through the study of the cooperative diffusion coefficient by the gradient diffusion technique [20].

The close correspondence between these experimental data with the expected 1.0 value supports the scaling arguments. It could also be argued that the same result is derived from a simple extrapolation of the sedimentation formula developed for the dilute regime :

$$
S_{\mathrm{q}}=S_{0}\left(1+k_{\mathrm{s}} c\right)^{-1}
$$

Indeed

$$
S_{\mathrm{q}} \rightarrow S_{0}\left(k_{\mathrm{s}} c\right)^{-1} \sim c^{-1} \quad \text { if } \quad k_{\mathrm{s}} c \gg 1 .
$$

However this approach cannot describe our experiments satisfactorily : i) the prefactor for $S \propto c^{-1}$ calculated using our independent determination of $S_{0}$ and $k_{\mathrm{s}}$ is too small by a factor of 2 compared with our experimental value in the semi-dilute regime, ii) more important, such a simple formula has no sound theoretical basis for solution concentrations where $k_{\mathrm{s}} c$ becomes of order unity, iii) last, it must be realized that the physical processes in the semi-dilute regime involve the flow of solvent through a porous plug of mesh size $\xi_{H}[9,18]$ rather than the flow of solvent around relatively impenetrable coils as in the dilute regime.

The molecular weight dependence of the cross-over concentration, $c^{*} \sim M^{-0.50}$, is also in agreement with the predictions. It should be remarked however that the absolute values given here for $c^{*}$ are somewhat lower (up to a factor of 6 roughly) than the corresponding data obtained by viscometry $[16,17]$ or by osmotic pressure [18a, 21, 22] measurements. One possible explanation may be that the sharpness of the cross-over concentration region depends on the property studied and considerable rounding-off may occur in the curves, making difficult a precise determination of the $c^{*}$ position.

If we now compare these hydrodynamic results for $R_{\mathrm{H}}$ and $\xi_{\mathrm{H}}$ with the corresponding static data, we find that the power law exponents take identical values within experimental accuracy. Several determinations of the static radius of gyration $R_{\mathrm{G}}$ showing that $R_{\mathrm{G}} \sim M^{0.50}$ can be found in the literature $[23,24]$. On the other hand, there are two reports by small angle neutron scattering [25] and by osmotic pressure techniques [18] showing that the static correlation length $\xi_{\mathrm{s}}$ scales as $\xi_{\mathrm{s}} \sim c^{-1}$. We thus corroborate, at least in theta solvents, one of the assumption of the scaling approach, i.e. the existence of a single power law exponent to describe the spatial properties of polymer solutions in the dilute and also in the semidilute regimes. It is necessary however at this stage to point out that the scaling approach makes no prediction on absolute values and that the different parameters, e.g., $\xi_{\mathrm{H}}$ and $\xi_{\mathrm{s}}$, may simply be proportional to each other.

In conclusion, we have measured the scaling exponents for the hydrodynamic radius of gyration, the cross-over concentration and the dynamic correlation length of quasi-ideal theta solutions. In all cases, data are found to be in good agreement with their static analogs and also with the earlier dynamic determinations.

Acknowledgments. - This research was supported by a contract D.G.R.S.T. " Récupération du Pétrole ". One of us (P. V.) has benefited from a scholarship of the Republicka Zajednica nauke Srbije, Beograd. 


\section{References}

[1] Flory, P. J., Principles of polymer chemistry (Cornell University Press, Ithaca, New York) 1953.

[2] De Gennes, P. G., Phys. Lett. 38A (1972) 339.

DE GENNES, P. G., Scaling concepts in polymer physics (Cornell University Press, Ithaca) 1979.

[3] Des Cloizeaux, J., J. Physique 36 (1975) 281.

[4] Daoud, M., Cotton, J. P., Farnoux, B., Jannink, G., Sarma, G., Benort, H., Duplessix, R., Picot, C. and De Gennes, P. G., Macromolecules 8 (1975) 804.

[5] Adam, M. and Delsanti, M., Macromolecules 10 (1977) 1229. AdLer, R. S. and Freed, K. F., J. Chem. Phys. 70 (1979) 3119.

[6] Weill, G. and des Cloizeaux, J., J. Physique 40 (1979) 99. See also : Stockmayer, W. H. and Albrecht, A. C., J. Polym. Sci. 32 (1958) 215.

[7] Yamakawa, H., Modern Theory of Polymer Solutions (Harper and Row, New York) 1971.

Farnoux, B., Boue, F., Cotton, J. P., Daoud, M., Jannink, G., Nierlich, M. and De Gennes, P. G., J. Physique 39 (1978) 77.

[8] SchachmaN, H. K., Ultracentrifugation in biochemistry (Academic Press, New York) 1959.

[9] Brochard, F. and De Gennes, P. G., Macromolecules 10 (1977) 1157.

[10] Daoud, M. and Jannink, G., J. Physique 37 (1976) 973.

[11] Destor, C. and Rondelez, F., Polymer 22 (1981) 67.

[12] Pyun, C. W. and Fixman, M., J. Chem. Phys. 41 (1964) 937. MulderiJe, J. J. H., Macromolecules 13 (1980) 1526.

For a recent review, see also : VRENTAS, J. S., LiU, H. T. and Duda, J. L., J. Polym. Sci., Polym. Phys. Ed. 18 (1980) 1633.
[13] MulderiJe, J. J. H., Macromolecules 13 (1980) 1207.

[14] Kotaka, T. and Donkai, N., J. Polym. Sci. 6 (1968) 1457 and references therein.

[15] Einaga, Y., Miyaki, Y. and Fujita, H., J. Polym. Sci., Polym. Phys. Ed. 17 (1979) 2103.

[16] See Graessley, W. W., Polymer 21 (1980) 258, Adv. Polym. Sci. 16 (1974) 1.

[17] FERRY, J. D., Macromolecules 13 (1980) 1719.

[18] a) Roots, J. and Nyström, B., Polymer 20 (1979) 148.

b) Nyström, B., Roots, J. and Bergman, R., Polymer 20 (1979) 157.

[19] MijnliefF, P. F. and JASPERS, W. J. M., Trans. Faraday Soc. 67 (1971) 1837.

[20] Roots, J. and Nyström, B., Macromolecules 13 (1980) 1595.

[21] Krigbaum, W. and Geymer, D., J. Am. Chem. Soc. 81 (1959) 1859.

[22] Candau, F., Strazielle, C. and Benoit, H., Eur. Polym. J. 12 (1976) 95.

[23] Miyaki, Y., Einaga, Y. and Fujita, H., Macromolecules 11 (1978) 1180.

[24] Cotton, J. P., Decker, D., Farnoux, B., Jannink, G., Ober, R. and Picot, C., Phys. Rev. Lett. 32 (1974) 109.

[25] Cotton, J. P., Nierlich, M., Boue, F., Daoud, M., FarNOUX, B., JANNink, G., Duplessix, R. and PiCOT, C., J. Chem. Phys. 65 (1976) 1101. 